\title{
Association of Circadian Rhythm With Mild Cognitive Impairment Among Pneumoconiosis Workers in Hong Kong: a Cross-sectional Study
}

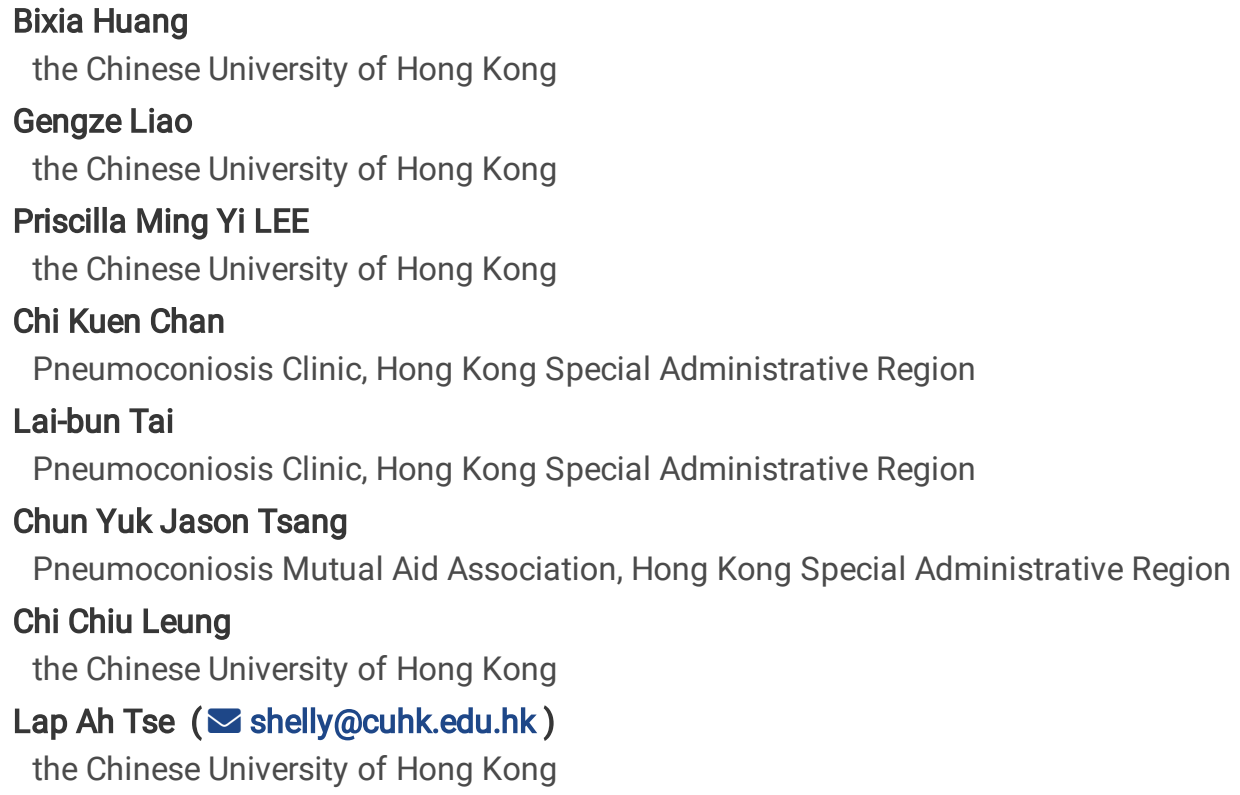

\section{Research Article}

Keywords: Circadian activity rhythm, cognitive function, mild cognitive impairment, pneumoconiosis

Posted Date: January 24th, 2022

DOI: https://doi.org/10.21203/rs.3.rs-1259617/v1

License: (c) (i) This work is licensed under a Creative Commons Attribution 4.0 International License. Read Full License 


\section{Abstract}

Background Weakened circadian rhythm was associated with mild cognitive impairment $(\mathrm{MCl})$ in the general population, but it remains unclear among pneumoconiosis patients and this knowledge gap was rectified in this study.

Methods This cross-sectional study consisted of 186 male pneumoconiosis patients and 208 age-matched healthy community men who wore a wrist actigraphy for 168 hours and completed a face-to-face questionnaire containing information on sociodemographic, lifestyle behavior, and anthropometric measurements. Circadian activity rhythm was characterized by a cosine model and the parameters included percent rhythm, amplitude, the midline estimating statistic of rhythm (MESOR), and acrophase. Values below the corresponding medians of the circadian rhythm parameters represented weakened circadian rhythm. Cognitive function and $\mathrm{MCl}$ or cognitive impairment was assessed by the Cantonese version of Mini-Mental State Examination (CMMSE). Multivariate logistic regression models were used to evaluate the relationships of circadian rhythm with the prevalence of $\mathrm{MCl}$ and composite outcome of $\mathrm{MCl}$ plus cognitive impairment.

Results The mean age of the pneumoconiosis patients was $71.3 \pm 7.8$ years with the prevalence of $\mathrm{MCl}$ and composite outcome of $38.7 \%$ and $50.0 \%$. Pneumoconiosis patients had worse cognition and dampened circadian rhythm than the community referents. Compared with the community referents or pneumoconiosis patients with robust circadian rhythm, pneumoconiosis patients with weakened circadian rhythm was consistently associated with increased risk of $\mathrm{MCl}$ and composite outcome, though the significant association was only for MESOR and the composite outcome with an adjusted OR of 2.01 (95\%: 1.03-3.94). A delayed phase of circadian rhythm was insignificantly associated with $\mathrm{MCl}$ and composite outcome.

Conclusions Weakened circadian activity rhythm among pneumoconiosis workers was positively associated with the prevalence of $\mathrm{MCl}$ and composite outcome. Our study suggests that intervention on improving circadian rhythm may mitigate the cognitive deterioration in pneumoconiosis workers.

\section{Background}

Pneumoconiosis is the most common interstitial occupational lung disease, mainly including silicosis, asbestosis, and coal workers' pneumoconiosis (1). Globally, 251,299 workers died from pneumoconiosis in 1990, and the death toll slightly rose to 259,700 in 2013 (2). In Hong Kong, silicosis has been ranked as the top third occupational disease, which along with asbestosis has constantly contributed to $19.4 \%$ of overall prescribed occupational diseases over the last decade (2009 2019) (3). The development of pulmonary fibrosis could continue even after the dust exposure has ceased for many years. Some of the pneumoconiosis workers may further suffer from hypoxemia - inflammation, oxidative stress - brain parenchymal and vascular changes (4). Evidence in the general aged population and patients with chronic obstructive pulmonary disease (COPD) has shown that these pathological changes were associated with the development of hippocampal atrophy and elevated level of amyloid- $\beta$ protein in the brain $(5,6)$, which were evident markers of cognitive decline and cognitive impairment (7).

On the other hand, as pneumoconiosis is a typical kind of restrictive lung disease, pneumoconiosis workers may also encounter sleep disturbance and poor sleep quality resulting from the related nocturnal cough and breathing difficulties. The sleep disruption may cause pneumoconiosis patients more prone to be exposed to light at night and physical inactivity, which may consequently disrupt their circadian rhythm. Circadian rhythm is crucial for mammals to maintain synchrony between internal physiology, behavior, and external fluctuating environment (8). The loss of this synchrony might cause circadian misalignment and further lead to a series of negative health outcomes including cardiometabolic diseases (9), inflammatory diseases (10), cancer (11), and neurodegenerative diseases (12). Recent research in the general aged population has raised great interest in a positive association between circadian rhythm disruption and cognitive impairment (13-15), and interventions targeted at improving circadian rhythms such as light therapy (16), melatonin supplement (17), and promotion of physical exercise (18) have shown potential beneficial effects on preventing cognitive decline.

Pneumoconiosis workers are hypothesized to be more vulnerable to the weakened circadian rhythm and impaired cognitive function. However, there has been no study investigating the rest-activity circadian rhythm pattern in pneumoconiosis workers, and the association of circadian rhythm with the cognitive function in pneumoconiosis workers remained unknown. This study aimed to characterize circadian rhythm among pneumoconiosis workers and its association with mild cognitive impairment (MCl) and cognitive impairment, using community people as the reference. 


\section{Methods}

\section{Study design and subject recruitment}

This cross-sectional study enrolled 205 male pneumoconiosis workers and 214 male community referents from May 2019 to September 2020 and all were invited to wear Actigraphy for a consecutive 168 hours of measurement of sleep and circadian rhythm. Ethics approval of this study was obtained from the Joint Chinese University of Hong Kong - New Territories East Cluster Clinical Research Ethics Committees (CRE-2018.626) and written informed consent was obtained from each participant before the interview was conducted. This report follows the Strengthening the Reporting of Observational Studies in Epidemiology (STROBE) reporting guideline for cross-sectional studies.

All pneumoconiosis workers included in this report were recruited during the annual interviews organized by the Pneumoconiosis Compensation Fund Board in 2018 and 2019. In Hong Kong, according to the Pneumoconiosis and Mesothelioma (Compensation) Ordinance (19), 'pneumoconiosis' refers to 'fibrosis of the lungs due to dust of free silica or asbestos, or dust containing free silica or asbestos, whether or not such disease is accompanied by tuberculosis of the lungs, or any other disease of the pulmonary or respiratory organs caused by exposure to such dust'. A medical examination is required for diagnosing pneumoconiosis (profusion category $1 / 0$ or higher). The diagnosis of pneumoconiosis was determined by the Pneumoconiosis Medical Board following the criteria of the International Labor Organization including silicosis and asbestosis (20). Workers who are Hong Kong residents aged $\geq 30$ years and currently employed in the construction or renovation industry for at least 1 year are eligible to claim compensation from the Pneumoconiosis Compensation Fund Board.

Community referents were recruited through poster advertisements in collaboration with five non-governmental organizations and seven district council members located in different areas of Hong Kong, including Kwun Tong, Kowloon City, Tsuen Wan, Sham Shui Po, and Kwai Tsing Districts. To be eligible, community referents ought to be: 1) Hong Kong Chinese male residents aged 60 years old or above (age-matched in 5 years with the pneumoconiosis workers); 2) Cantonese or Mandarin speakers; 3 ) able to complete the survey independently. We excluded participants who have physician-diagnosed mental health disorders or other medical conditions that prevented them from completing the survey such as serious hearing or visual impairment.

A total of 205 male pneumoconiosis patients and 214 community subjects completed a standard questionnaire interview and cognitive function tests, and they were further invited to wear the GENEActive device for 7 days. During the assessment, 6 pneumoconiosis workers withdrew for the following reasons: allergy (2), hospitalization (1), busyness (1) and watches not returned (2); and 1 community subject had not returned the watch. After further excluding 7 participants with incomplete data of CMMSE (4 patients and 3 community subjects) and 11 participants with incomplete data on actigraphy assessment (recorded $<120$ hours) (9 patients and 2 community subjects), resulting in an overall 186 pneumoconiosis workers and 208 community subjects being included in the final analysis. The detailed subject recruitment framework is shown in Additional file 1: Figure S1.

\section{Data collection and variable specification}

Trained researchers conducted a face-to-face interview with every participant using a standardized questionnaire containing information on socio-demographic, lifestyle habits, medical history, sleep medication use, family history of dementia, depression and anxiety, physical activity, and sleep quality. Age was categorized as $<65,65-74$, or $\geq 75$ years. Education attainment was categorized as $0-3,4-6$, or $>6$ years. Marital status was categorized as single/divorced/widowed or married/cohabitating. Employment status was categorized as retired or employed. Smoking status was categorized as never smoker, former smoker, and current smoker. A never smoker referred to one who had never smoked as much as 20 packs of cigarettes or 12 oz of tobacco in a lifetime, or 1 cigarette a day or 1 cigar a week for 1 year. If a smoker has quit smoking for 1 year or more, then he was considered as a former smoker (21); otherwise, he was considered as a current smoker. Alcohol drinking was classified as never drinker, former drinker, and current drinker. A never drinker referred to one who had never drunk as much as once per month and had been lasting over half a year. A drinker was defined if he or she drank alcohol at least once per month and had been lasting over half a year. If the drinker has quit drinking for 1 year or more, then he was considered as a former drinker; otherwise, he was a current drinker. Participants who drank tea or coffee more than twice weekly for at least 6 months were defined as tea drinkers or coffee drinkers, respectively. Body mass index (BMI) was categorized as normal weight $\left(<24 \mathrm{~kg} / \mathrm{m}^{2}\right)$, overweight $\left(24-27.9 \mathrm{~kg} / \mathrm{m}^{2}\right)$, and obesity $\left(\geq 28 \mathrm{~kg} / \mathrm{m}^{2}\right)$, according to the cut-off points proposed by the Working Group on Obesity in China. Anxious and depressive symptoms were assessed by the Hospital Anxiety and Depression Scale (HADS) (22) and both anxiety and depression were categorized as normal (0-7), borderline abnormal (8-10), and 
abnormal (11-21). Physical activity was assessed with the short interviewer-administrated International Physical Activity Questionnaire (IPAQ) and was categorized as low, moderate, and high (23). Subjective sleep quality was examined by the Pittsburgh Sleep Quality Index (PSQI), and a poor sleeper was defined if his/her PSQI score was > 5 (24). Anthropometric information was measured by the body composition monitor (model: BC-545N; TANITA corporation), including body weight and percent body fat. Height and weight were measured with the subjects barefoot and wearing undergarments. Waist circumference was measured at the midpoint between the lowest rib and the iliac crest (25). Body mass index (BMI) was calculated as the weight in kilograms divided by the square of the height in meters $\left(\mathrm{kg} / \mathrm{m}^{2}\right)$. Handgrip strength was measured by the hydraulic hand dynamometer (Jamar; Lafayette, USA). The maximal handgrip strength measurement from a single trial on either hand was included in the analyses (26).

\section{Outcome assessment of mild cognitive impairment and cognitive impairment}

The Cantonese version of Mini-Mental State Examination (CMMSE) was used to measure the cognitive function of study participants. The CMMSE was translated and validated by Chiu et al. to assess dementia among Hong Kong Chinese (27), which contains 30 items to measure various cognitive domains including orientation, registration, attention and calculation, immediate and short-term recall, and language, with a score ranging from 0 to 30. A lower CMMSE score indicates a worse cognitive function of the participant. We adopted the cut-off levels of CMMSE proposed in a previous study (28) to define the cognitive impairment, i.e., 27-30, 21-26, 0-20 were determined as normal cognition, mild cognitive impairment, and moderate-severe cognitive impairment, respectively.

The primary outcome was mild cognitive impairment plus moderate-severe cognitive impairment (i.e., composite outcome). As only a limited number of cognitive impairment cases were obtained, a separate analysis only for mild cognitive impairment was also examined.

The Hong Kong version of Montreal Cognitive Assessment (HK-MoCA) was also used to measure the cognitive function of study participants in the sensitivity analysis, which has been validated by Yeung et al. and Wang et al. $(21,22)$. The age and education corrected cutoff scores were adopted to classify the severity of cognitive impairment. A score of $>7^{\text {th }}, 7^{\text {th }}-2^{\text {nd, }}$ and $\leq 2^{\text {nd }}$ percentile was determined as normal cognition, $\mathrm{MCl}$, and cognitive impairment, respectively (23). Since there were no percentile cutoff scores reported for subjects $<65$ years old in the manual, subjects in this age strata were referred to the percentile scores of the 65-69 age stratum in this study.

\section{Assessment of circadian activity rhythms}

Each pneumoconiosis worker and community subject wore a GENEActiv Original (Activinsights Company, UK) device on his nondominant wrist continuously for 168 hours without removal even during sleep or bathing (measurement frequency $100 \mathrm{~Hz}$, sampling rate corresponding to $1 \mathrm{~min}$ ). The assessment of circadian rhythm parameters had been described previously (29). The actigraphy detects and records movements in three mutually vertical axes $(x, y$, and $z)$ and real-time skin temperature. A gravity-subtracted sum of vector magnitudes (SVM) was automatically calculated with data of the three axes $(x, y, a n d z)$ and a formula defined by the manufacturer: SVMg $s=\left[\left(x^{2}+y^{2}+z^{2}\right)^{1 / 2}-1 g\right](30)$. Data of SVM were then imported into the Chronos-Fit program (v. 1.06) to compute four parameters, namely percent rhythm, double amplitude, the midline estimating statistic of rhythm (MESOR), and acrophase (31). Non-wearing time was determined by reviewing the activity records outputted from the GENEActiv software and self-reported by the interviewees. The non-wearing periods should present low and steady SVM readings. For each participant, the data of non-wearing periods were excluded from the calculation of their parameters. The recordings lasted from 5 to 7 consecutive days, including a weekend. If the sum length of wearing was less than $120 \mathrm{~h}(5 / 7$ of $168 \mathrm{~h})$, the wearing was considered incomplete, and its data were not analyzed.

There were no available standard cutoff points for classifying the levels of percent rhythm, amplitude, MESOR, and acrophase. Thus, we used medians of the four parameters to dichotomize participants with different exposure levels. Percent rhythm, amplitude, and MOSER below the corresponding medians represented weak circadian rhythms, and the robust rhythm was defined if the actual measurement is equal to or above the median. Overall, the larger value of the above three circadian parameters, the more robust the circadian rhythm. Acrophase was used to assess if the circadian phase was delayed or advanced compared with the median level of the participants.

\section{Statistical analyses}


Differences in the basic characteristics, cognitive function, and circadian rhythm parameters between patients and community subjects were compared using the chi-square test or Fisher's exact test for categorical variables, and t-test or Kruskal-Wallis test for continuous variables, according to the data distribution. We dichotomized all participants using the median levels of the four circadian rhythm parameters to examine the association between weakened circadian rhythm and the prevalence of $\mathrm{MCl}$ and composite outcome. To illustrate whether pneumoconiosis workers with weakened circadian rhythm parameters had a higher risk of $\mathrm{MCl}$ and composite outcome, we further classified study subjects into four sub-groups according to the status of pneumoconiosis (yes/no) and circadian activity rhythm (above/below median levels), using community subjects with robust circadian activity rhythm parameters as the reference. Unconditional multivariable logistic regression was performed to calculate the adjusted odds ratios (ORs) for the association of being diagnosed with pneumoconiosis and levels of circadian rhythm parameters with the presence of $\mathrm{MCl}$ and composite outcome, after adjustment of age (years), education attainment (years), marital status, employment, BMI, stroke,

hypertension, diabetes, cardiovascular disease, sleep medication use, family history of dementia, smoking, alcohol drinking, tea drinker, coffee drinker, anxiety, depression, physical activity, waist circumference, percent body fat, handgrip strength, and poor sleep.

Sensitivity analyses were carried out to examine the robustness of the association between circadian rhythm and $\mathrm{MCl}$ and composite outcome by evaluating $\mathrm{MCl}$ and cognitive impairment with HK-MoCA. All analyses were conducted using SAS statistical software 9.4 (SAS Institute Inc., Cary, NC) and Stata 15 (StataCorp, College Station, TX, US). All tests were two-sided, and a $P$-value $<0.05$ was considered statistically significant.

\section{Results}

\section{Sociodemographic characteristics and prevalence of $\mathrm{MCl}$ and cognitive impairment among pneumoconiosis patients}

Among 186 pneumoconiosis workers included in this report, 182 workers were diagnosed with silicosis and 4 workers were diagnosed with asbestosis. Overall, the average age of the pneumoconiosis patients was 71.3 (s.d.: 7.8 ) years, with $77.4 \%$ current or former smokers and $82.8 \%$ low education attainment (<6 years). Compared with the community subjects, pneumoconiosis patients were more likely to be lower educated and had lower waist circumference, less overweight or obese, and disease history of stroke or with a family history of dementia; but they had a higher proportion of married/cohabitating, retired, former smoker, former alcohol drinker or tea drinker and poor sleeper (all $p<0.05$ ) (as shown in Table 1).

Table 2 summarizes cognitive function and status of cognitive impairment measured by CMMSE among the pneumoconiosis patients with the comparison of community referents. Pneumoconiosis workers presented a significantly lower global score of 25.7 (s.d.: 3.4 ) than that of the community referents $(26.4$, s.d.: 3.4$)(p=0.045)$. The poorer global cognitive function in pneumoconiosis patients was mainly attributed to the poor score of the sub-item "orientation" $(p=0.011)$. In addition, the prevalence of the composite outcome, $\mathrm{MCl}$, and cognitive impairment $(50 \%, 38.7 \%$, and $11.3 \%)$ in pneumoconiosis patients measured by CMMSE were significantly higher than those of the community referents $(36.5 \%, 29.3 \%$, and $7.2 \%)$.

\section{The pattern of circadian activity rhythm and association with $\mathrm{MCl}$ and the composite outcome}

Table 3 demonstrated that the pneumoconiosis patients had relatively lower values of all circadian activity rhythm parameters than those of the community participants, but the significant differences were only for MESOR (236.4 vs. 268.2, $p=0.008)$ and acrophase (13.5 vs. $14.1, p=0.029)$.

Associations of circadian rhythm parameters with cognitive function and prevalence of $\mathrm{MCl}$ and composite outcome among pneumoconiosis patients are presented in Table 4. By taking patients who had the robust circadian rhythm parameter as the reference, patients with weakened circadian rhythm were associated with increased prevalence of $\mathrm{MCl}$ and composite outcome, but the marginally significant association was only observed for the association between low MESOR value and composite outcome.

To understand further if pneumoconiosis patients with weakened circadian rhythm had a higher prevalence of cognitive impairment, we conducted additional analysis by using community subjects with robust circadian rhythm as a reference. As shown in Table 5, pneumoconiosis patients with a lower level of circadian rhythm parameters (i.e., percent rhythm, amplitude, and MESOR) were consistently related to a higher risk of $\mathrm{MCl}$ and composite outcome, despite the significant association was only observed for MESOR and composite outcome. In addition, a higher risk of $\mathrm{MCl}$ was indicated among pneumoconiosis patients with a delayed phase of restactivity rhythm though there was not statistically significant. 
Sensitivity analyses were conducted by using HK-MoCA to measure $\mathrm{MCl}$ and cognitive impairment and exclusion of community subjects recruited during COVID-19 outbreaks in Hong Kong (Additional file 2: Table S1 and Additional file 3: Table S2), a similar pattern was suggested for the association of circadian rhythm parameters with $\mathrm{MCl}$ and composite outcome.

\section{Discussion}

This study is the first to investigate the circadian rhythm pattern and its association with $\mathrm{MCl}$ and composite outcome of $\mathrm{MCl}$ plus cognitive impairment among pneumoconiosis workers. We observed significant disturbances in cognition and circadian activity rhythm in patients with pneumoconiosis. Compared with the community referents, pneumoconiosis patients with weakened circadian activity rhythm and delayed circadian/activity phase had a higher prevalence of $\mathrm{MCl}$ and composite outcome, suggesting that weakened circadian rhythm in pneumoconiosis workers may be a novel marker of impaired cognition, which may potentially serve as a therapeutic target for mitigating the increasing health problem related to cognitive impairment.

Previous studies on the rest-activity pattern were mostly derived from patients with neurodegeneration (12), cardiometabolic diseases (9), cancer (32), and mental disorders (33). Evidence about circadian activity rhythm in respiratory diseases (except for lung cancer) is very scarce. Nunes et al. (34) compared the circadian rest-activity rhythm between 26 clinically stable COPD patients and 15 controls and found that COPD patients had a decrease in the relative amplitude mean $(0.696 \pm 0.134 \mathrm{vs} 0.833 \pm 0.093)$ than the controls. Although there was no statistically significant finding in amplitude, our study found a statistically significant lower level of MESOR in pneumoconiosis patients, which provided additional evidence of circadian rhythm disturbances in patients with chronic respiratory diseases.

The association between circadian activity rhythm and cognitive function was revealed in the non-demented older population in both cross-sectional and prospective studies. A study conducted in 2,754 men (mean age of 76 years) in the US reported that lower baseline amplitude, robustness (pseudo-F-statistic), and MESOR, as well as advanced acrophase, were associated with greater cognitive decline over 3.4 years of follow-up (13). Another study conducted in 1287 women (mean age of 83 years) found that lower amplitude and robustness, and delayed rhythms at baseline were associated with worse cognitive performance (15), which in turn increased risks of dementia and $\mathrm{MCl}$ over 3.4 years of follow-up (7). Since sleep and circadian rhythm are tightly coupled, circadian rhythms might affect cognition through both sleep-dependent and sleep-independent pathways (35). Animal and human studies have proposed some potential mechanisms for the circadian-cognition relationship (12), which could be summarized as 1) alter sleep timing and cause sleep deprivation, thus regulating amyloid- $\beta$ and Tau dynamics and increase inflammatory and neuronal injury $(36,37) ; 2)$ regulate inflammatory activation, the circadian clock is critical for innate immune homeostasis in the brain, conversely, circadian dysfunction could cause neuroinflammation and exacerbate neuropathology $(38)$; 3 ) circadian misalignment may directly regulate protein homeostasis and regulate the blood-brain barrier permeability for clearance of protein aggregates, thus influence protein aggregation (39); 4) oxidative stress (40).

In line with the findings in the general population, the results of our multivariate analyses consistently indicated a higher prevalence of $\mathrm{MCl}$ and the composite outcome of $\mathrm{MCl}$ plus cognitive impairment in patients with weakened circadian activity rhythm (lower values of amplitude and MESOR). Our results also suggested a more robust circadian rhythm-cognition relationship in pneumoconiosis than in the general population.

This study has several strengths. First, we recruited community subjects as referents using the same protocol within our study to avoid potential heterogeneities when comparing the findings with other studies. Second, the rhythm on weekdays and weekends could be substantially different (41). The long actigraphy wearing time (120 to 168 hours including weekdays and weekends) made us more accurately capture the circadian patterns of the study population. Third, our study has a good response rate and compliance, as $95.7 \%$ of the participants (401 out of 419 subjects who agreed to wear the device) provided credible actigraphy data after the long device wearing, which could minimize the chances of selection bias. Finally, we collected comprehensive data of possible cofounders on demographic characteristics, socioeconomic status, lifestyle factors, and medical history to reduce the residual confounding bias.

This study has several limitations. First, the cross-sectional design of this study may limit us from causal inference, however, this study added value to the scientific literature as evidence in circadian rhythm and the cognitive outcome is very limited in pneumoconiosis patients. Second, sixty community subjects in the study were recruited between June 23 to July 09, 2020, just after the $2^{\text {nd }}$ wave of the COVID-19 outbreak in Hong Kong (42). The possible physical inactivity due to sustained quarantine and social distancing (43) may adversely influence participants' circadian rhythm. We performed a sensitivity analysis excluding the community 
subjects recruited within this period and a significantly decreased amplitude was observed in pneumoconiosis patients when compared to that of the community subjects (as shown in Additional file 3: Table S2). Thus, the overall circadian activity of the community referents may be underestimated. However, we expected that this would have biased our findings toward the null. Third, we used medians as cut-offs for each circadian rhythm parameter because there are no standard criteria to define weak and robust circadian rhythm. Meanwhile, the sample size restricted us from further dividing participants into tertiles or quartiles of circadian rhythm parameters to investigate the biological gradient (dose-response) of circadian disruption. We used the composite outcome of $\mathrm{MCl}$ plus cognitive impairment as the primary outcome to improve statistical power. Finally, all our study participants were men, so the generalization to the whole population including women could be limited.

\section{Conclusions}

The weakened circadian activity rhythm of pneumoconiosis workers was positively associated with the prevalence of $\mathrm{MCl}$ and composite outcome of $\mathrm{MCl}$ plus cognitive impairment. Our study suggests that the improvement of circadian rhythm may mitigate the cognitive deterioration in pneumoconiosis workers.

\section{List Of Abbreviations}

BMI: Body mass index; Cl: Confidence interval; CMMSE: Cantonese version of Mini-Mental State Examination; COPD: Chronic obstructive pulmonary disease; COVID-19: Coronavirus disease 2019; HADS: Hospital Anxiety and Depression Scale; HK-MoCA: Hong Kong version of Montreal Cognitive Assessment: IPAQ: International Physical Activity Questionnaire; IQR: Interquartile range; MCI: Mild cognitive impairment; MESOR: Midline estimating statistic of rhythm; OR: Odds ratio; PSQI: Pittsburgh Sleep Quality Index; SD: Standard deviation; SVM: Sum of vector magnitudes.

\section{Declarations}

\section{Ethics approval and consent to participate}

The study obtained ethics approval from the Joint Chinese University of Hong Kong - New Territories East Cluster Clinical Research Ethics Committee (CRE-2018.626). Written informed consent was obtained from each participant before the interview was conducted.

\section{Consent for publication}

Not applicable.

\section{Availability of data and materials}

The datasets used and/or analysed during the current study are available from the corresponding author on reasonable request.

\section{Competing interests}

The authors declare no competing interests.

\section{Funding}

This study was substantially supported by a grant from the Pneumoconiosis Compensation Fund Board of the Hong Kong Special Administrative Region, China. The funding source had no role in the study design, data collection, data analysis, decision to publish, preparation of the manuscript, or interpretation of the finding.

\section{Authors' contributions}

$\mathrm{BH}$ reviewed the literature; collected, organized and analyzed the data; and drafted the manuscript. GL and PMYL helped in data collection, data management and reviewed the manuscript. CKC, LBT and CCL gave comments and reviewed the manuscript. CYJT managed the data collection in the field and reviewed the manuscript. LAT is the principal investigator of the project, designed and supervised the entire study, critically reviewed and revised the manuscript. The authors read and approved the final manuscript.

\section{Acknowledgements}


Our great thanks are to the staffs of the Pneumoconiosis Mutual Aid Association, Hong Kong SAR, for their generous help in data collection. The authors would like to thank, Ms. KWOK Ho Ling Bonnie, Ms. MO Hoi Wan Ocean, Ms. CHAN Yunn Kiu Casey and other interviewers for their assistance in patients' recruitment and data collection.

\section{References}

1. Cullinan P, Reid P. Pneumoconiosis. Primary Care Respiratory Journal. 2013;22(2):249-52.

2. Aboyans V, Collaborators CoD. Global, regional, and national age-sex specific all-cause and cause-specific mortality for 240 causes of death, 1990-2013: a systematic analysis for the Global Burden of Disease Study 2013. The Lancet (British edition). 2015;385(9963):117-71.

3. Labour Department tgothkarotpsroC. https://www.labour.gov.hk/tc/osh/pdf/Bulletin2019_issue20_tc.pdf 2019 [Available from: https://www.labour.gov.hk/tc/osh/pdf/Bulletin2019_issue20_tc.pdf.

4. Zhai P, Li H, Zhao R, Li X, Wang H. Clinical characteristics of pneumoconiosis complicated with chronic obstructive pulmonary disease. Zhonghua lao dong wei sheng zhi ye bing za zhi= Zhonghua laodong weisheng zhiyebing zazhi= Chinese journal of industrial hygiene and occupational diseases. 2019;37(12):899-902.

5. Li J, Fei G-H. The unique alterations of hippocampus and cognitive impairment in chronic obstructive pulmonary disease. Respiratory research. 2013;14(1):140.

6. Dodd JW. Lung disease as a determinant of cognitive decline and dementia. Alzheimer's research \& therapy. 2015;7(1):32.

7. Villemagne VL, Burnham S, Bourgeat P, Brown B, Ellis KA, Salvado O, et al. Amyloid $\beta$ deposition, neurodegeneration, and cognitive decline in sporadic Alzheimer's disease: a prospective cohort study. The Lancet Neurology. 2013;12(4):357-67.

8. Reppert SM, Weaver DR. Coordination of circadian timing in mammals. Nature. 2002;418(6901):935-41.

9. Rüger M, Scheer FA. Effects of circadian disruption on the cardiometabolic system. Reviews in Endocrine and Metabolic Disorders. 2009;10(4):245-60.

10. Gombert M, Carrasco-Luna J, Pin-Arboledas G, Codoñer-Franch P. The connection of circadian rhythm to inflammatory bowel disease. Translational Research. 2019;206:107-18.

11. Sulli G, Lam MTY, Panda S. Interplay between circadian clock and cancer: new frontiers for cancer treatment. Trends in cancer. 2019;5(8):475-94.

12. Leng Y, Musiek ES, Hu K, Cappuccio FP, Yaffe K. Association between circadian rhythms and neurodegenerative diseases. The Lancet Neurology. 2019;18(3):307-18.

13. Rogers-Soeder TS, Blackwell T, Yaffe K, Ancoli-Israel S, Redline S, Cauley JA, et al. Rest-activity rhythms and cognitive decline in older men: the osteoporotic fractures in men sleep study. Journal of the American Geriatrics Society. 2018;66(11):2136-43.

14. Tranah GJ, Blackwell T, Stone KL, Ancoli-Israel S, Paudel ML, Ensrud KE, et al. Circadian activity rhythms and risk of incident dementia and mild cognitive impairment in older women. Annals of neurology. 2011;70(5):722-32.

15. Walsh CM, Blackwell T, Tranah GJ, Stone KL, Ancoli-Israel S, Redline S, et al. Weaker circadian activity rhythms are associated with poorer executive function in older women. Sleep. 2014;37(12):2009-16.

16. Forbes D, Blake CM, Thiessen EJ, Peacock S, Hawranik P. Light therapy for improving cognition, activities of daily living, sleep, challenging behaviour, and psychiatric disturbances in dementia. Cochrane Database of Systematic Reviews. 2014(2).

17. Jean-Louis G, von Gizycki H, Zizi F. Melatonin effects on sleep, mood, and cognition in elderly with mild cognitive impairment. Journal of pineal research. 1998;25(3):177-83.

18. Law LL, Barnett F, Yau MK, Gray MA. Effects of combined cognitive and exercise interventions on cognition in older adults with and without cognitive impairment: a systematic review. Ageing research reviews. 2014;15:61-75.

19. Cap. 360 PNEUMOCONIOSIS AND MESOTHELIOMA (COMPENSATION) ORDINANCE. 05/03/2015 ed1980.

20. Michel L. ILO International Classification of Radiographs of Pneumoconiosis. In: Stellman JM, ed. Encyclopaedia of occupational health and safety. 4nd. Geneva: International Labour Office. 1998.

21. Ferris B. Epidemiology Standardization Project (American Thoracic Society) Am Rev Respir Dis 118 (6 pt 2): 1-120. Find this article online. 1978.

22. Zigmond AS, Snaith RP. The hospital anxiety and depression scale. Acta psychiatrica scandinavica. 1983;67(6):361-70. 
23. Committee IR. Guidelines for data processing and Analysis of the International Physical Activity Questionnaire (IPAQ). Short and Long Forms. 2005 Nov. 2016.

24. Buysse DJ, Reynolds CF, Monk TH, Berman SR, Kupfer DJ. The Pittsburgh sleep quality index: A new instrument for psychiatric practice and research. Psychiatry Research. 1989;28(2):193-213.

25. Bonita R, Winkelmann R, Douglas KA, de Courten M. The WHO Stepwise approach to surveillance (STEPS) of non-communicable disease risk factors. Global behavioral risk factor surveillance: Springer; 2003. p. 9-22.

26. McGrath R, Robinson-Lane SG, Cook S, Clark BC, Herrmann S, O'Connor ML, et al. Handgrip strength is associated with poorer cognitive functioning in aging Americans. Journal of Alzheimer's Disease. 2019;70(4):1187-96.

27. Chiu H. Reliability and validity of the Cantonese version of mini-mental state examination-a preliminary study. J Hong Kong College Psychiatrists. 1994;4:425-8.

28. CADENZA Training Programme. Evidence based practice in dementia care 2012 [Available from: http://www.cadenza.hk/training/pdf/CTP004_web2_ch1_en.pdf.

29. Li W, Kwok CC-H, Chan DC-W, Wang F, Tse LA. Weak circadian rhythm increases neutropenia risk among breast cancer patients undergoing adjuvant chemotherapy. Breast cancer research and treatment. 2018;168(2):483-93.

30. GENEActiv Instruction Manual v 1.4. [Available from: https://49wvycy00mv4161561vrj345-wpengine.netdna-ssl.com/wpcontent/uploads/2019/06/geneactiv_instruction_manual_v1.4.pdf.

31. Marler MR, Gehrman P, Martin JL, Ancoli-Israel S. The sigmoidally transformed cosine curve: a mathematical model for circadian rhythms with symmetric non-sinusoidal shapes. Statistics in medicine. 2006;25(22):3893-904.

32. Sultan A, Choudhary V, Parganiha A. Worsening of rest-activity circadian rhythm and quality of life in female breast cancer patients along progression of chemotherapy cycles. Chronobiology International. 2017;34(5):609-23.

33. Castro J, Zanini M, Gonçalves BdSB, Coelho FMS, Bressan R, Bittencourt L, et al. Circadian rest-activity rhythm in individuals at risk for psychosis and bipolar disorder. Schizophrenia research. 2015;168(1-2):50-5.

34. Nunes DM, Gonçalves BS, Tardelli Peixoto CA, De Bruin VMS, Louzada FM, De Bruin PFC. Circadian rest-activity rhythm in chronic obstructive pulmonary disease. Chronobiology international. 2017;34(9):1315-9.

35. Mongrain V, La Spada F, Curie T, Franken P. Sleep loss reduces the DNA-binding of BMAL1, CLOCK, and NPAS2 to specific clock genes in the mouse cerebral cortex. PLoS One. 2011;6(10):e26622.

36. Ooms S, Overeem S, Besse K, Rikkert MO, Verbeek M, Claassen JA. Effect of 1 night of total sleep deprivation on cerebrospinal fluid $\beta$-amyloid 42 in healthy middle-aged men: a randomized clinical trial. JAMA neurology. 2014;71(8):971-7.

37. Holth JK, Fritschi SK, Wang C, Pedersen NP, Cirrito JR, Mahan TE, et al. The sleep-wake cycle regulates brain interstitial fluid tau in mice and CSF tau in humans. Science. 2019;363(6429):880-4.

38. Huang Z, Liu Q, Peng Y, Dai J, Xie Y, Chen W, et al. Circadian rhythm dysfunction accelerates disease progression in a mouse model with amyotrophic lateral sclerosis. Frontiers in neurology. 2018;9:218.

39. Hastings $\mathrm{MH}$, Goedert M. Circadian clocks and neurodegenerative diseases: time to aggregate? Current opinion in neurobiology. 2013;23(5):880-7.

40. Srinivasan V. Melatonin oxidative stress and neurodegenerative diseases. 2002.

41. Vitale JA, Roveda E, Montaruli A, Galasso L, Weydahl A, Caumo A, et al. Chronotype influences activity circadian rhythm and sleep: differences in sleep quality between weekdays and weekend. Chronobiol Int. 2015;32(3):405-15.

42. Hong Kong Department of Health. Coronavirus Disease (COVID-19) in HK 2020 [updated 20 February 2020. Available from: https://www.coronavirus.gov.hk/eng/index.html.

43. Woods J, Hutchinson NT, Powers SK, Roberts WO, Gomez-Cabrera MC, Radak Z, et al. The COVID-19 pandemic and physical activity. Elsevier; 2020.

\section{Tables}

Table 1 Comparisons of characteristics between pneumoconiosis workers and community subjects 


\begin{tabular}{|c|c|c|c|c|c|}
\hline \multirow[t]{2}{*}{ Characteristic } & \multicolumn{2}{|c|}{$\begin{array}{l}\text { Community referents } \\
(\mathrm{N}=208)\end{array}$} & \multicolumn{2}{|c|}{$\begin{array}{l}\text { Pneumoconiosis workers } \\
(\mathrm{N}=186)\end{array}$} & \multirow[t]{2}{*}{$P$ value } \\
\hline & $\mathbf{n}$ & $\%$ & $\mathbf{n}$ & $\%$ & \\
\hline Age group, years & & & & & 0.30 \\
\hline$<65$ & 28 & 13.5 & 34 & 18.3 & \\
\hline $65-74$ & 101 & 48.6 & 92 & 49.5 & \\
\hline$\geq 75$ & 79 & 38 & 60 & 32.3 & \\
\hline Education, years & & & & & $<0.001$ \\
\hline $0-3$ years & 44 & 21.2 & 78 & 41.9 & \\
\hline $4-6$ years & 68 & 32.7 & 76 & 40.9 & \\
\hline 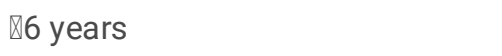 & 96 & 46.2 & 32 & 17.2 & \\
\hline Marital status & & & & & 0.002 \\
\hline Single/Divorced/Widowed & 37 & 17.8 & 14 & 7.5 & \\
\hline Married /cohabitation & 166 & 79.8 & 170 & 91.4 & \\
\hline Unknown & 5 & 2.4 & 2 & 1.1 & \\
\hline Employment & & & & & 0.045 \\
\hline Retired & 175 & 84.1 & 169 & 90.9 & \\
\hline Employed & 33 & 15.9 & 17 & 9.1 & \\
\hline Body Mass Index, $\mathrm{kg} / \mathrm{m}^{2}$ & & & & & 0.005 \\
\hline$\varangle 24$ & 91 & 43.8 & 105 & 56.5 & \\
\hline $24-27.9$ & 83 & 39.9 & 64 & 34.4 & \\
\hline$\geq 28$ & 33 & 15.9 & 13 & 7 & \\
\hline Unknown & 1 & 0.5 & 4 & 2.2 & \\
\hline \multicolumn{6}{|l|}{ Any medical condition } \\
\hline History of stroke & 19 & 9.1 & 6 & 3.2 & 0.016 \\
\hline History of hypertension & 98 & 47.1 & 89 & 47.8 & 0.88 \\
\hline History of diabetes & 51 & 24.5 & 33 & 17.7 & 0.10 \\
\hline History of cardiovascular disease & 28 & 13.5 & 22 & 11.8 & 0.63 \\
\hline Current sleep medication user & 9 & 4.3 & 5 & 2.7 & 0.43 \\
\hline Family history of dementia & 11 & 5.3 & 2 & 1.1 & 0.023 \\
\hline Smoking status & & & & & $<0.001$ \\
\hline Current smoker & 39 & 18.8 & 22 & 11.8 & \\
\hline Former smoker & 68 & 32.7 & 122 & 65.6 & \\
\hline Never smoker & 101 & 48.6 & 42 & 22.6 & \\
\hline Alcohol Drinking & & & & & $<0.001$ \\
\hline Current drinker & 35 & 16.8 & 37 & 19.9 & \\
\hline Former drinker & 31 & 14.9 & 63 & 33.9 & \\
\hline
\end{tabular}

Page 10/15 


\begin{tabular}{|llllll|}
\hline Never drinker & 142 & 68.3 & 86 & 46.2 & \\
\hline Tea drinker & 152 & 73.1 & 163 & 87.6 & $<0.001$ \\
\hline Coffee drinker & 68 & 32.7 & 47 & 25.3 & 0.11 \\
\hline Anxiety score of HADS & & & & & 0.60 \\
\hline Normal (0-7) & 183 & 88 & 159 & 85.5 & \\
\hline Borderline abnormal (8-10) & 18 & 8.7 & 15 & 8.1 & \\
\hline Abnormal (11-21) & 7 & 3.4 & 10 & 5.4 & \\
\hline Missing & 0 & 0 & 2 & 1.1 & \\
\hline Depression score of HADS & & & & & 0.15 \\
\hline Normal (0-7) & 165 & 79.3 & 158 & 84.9 & \\
\hline Borderline abnormal (8-10) & 23 & 11.1 & 17 & 9.1 & \\
\hline Abnormal (11-21) & 20 & 9.6 & 9 & 4.8 & \\
\hline Missing & 0 & 0 & 2 & 1.1 & \\
\hline Physical activity & & & & & 0.54 \\
\hline Low & 40 & 19.2 & 32 & 17.2 & \\
\hline Moderate & 107 & 51.4 & 106 & 57 & \\
\hline High & 61 & 29.3 & 48 & 25.8 & \\
\hline Poor sleep quality & 109 & 52.4 & 141 & 75.8 & $<.001$ \\
\hline & Mean & SD & Mean & SD & \\
\hline Waist circumference, cm & 89.5 & 10.1 & 86.2 & 9.1 & \\
\hline Handgrip strength, kg & 7.6 & 7.8 & 28.6 & 8.4 & \\
\hline Percent body fat, \% & 6.0 & 22.0 & 6.4 & \\
\hline
\end{tabular}

Abbreviations: BMI, body mass index; HADS, Hospital Anxiety and Depression Scale; SD, standard deviation.

Table 2 Distribution of cognitive function measured by CMMSE in pneumoconiosis patients and community referents 


\begin{tabular}{|c|c|c|c|c|c|}
\hline \multirow{3}{*}{ Variable } & \multirow{2}{*}{\multicolumn{2}{|c|}{$\begin{array}{l}\text { Community } \\
\text { referents }(\mathrm{N}=208)\end{array}$}} & \multirow{2}{*}{\multicolumn{2}{|c|}{$\begin{array}{l}\text { Pneumoconiosis } \\
\text { workers }(\mathrm{N}=186)\end{array}$}} & \multirow[t]{3}{*}{$P$-value } \\
\hline & & & & & \\
\hline & Mean & SD & Mean & SD & \\
\hline Global score & 26.4 & 3.4 & 25.7 & 3.4 & 0.045 \\
\hline \multicolumn{6}{|l|}{ Component scores } \\
\hline 1. Orientation & 9.41 & 1.27 & 9.09 & 1.22 & 0.011 \\
\hline 2. Registration & 2.86 & 0.52 & 2.87 & 0.43 & 0.92 \\
\hline 3. Attention and calculation & 3.73 & 1.6 & 3.65 & 1.59 & 0.64 \\
\hline 4. Recall & 2.12 & 0.98 & 2.03 & 1.01 & 0.35 \\
\hline \multirow[t]{2}{*}{ 5. Language } & 8.24 & 1.11 & 8.04 & 1.25 & 0.098 \\
\hline & $\mathbf{n}$ & $\%$ & $\mathbf{n}$ & $\%$ & \\
\hline Status of cognitive impairment & & & & & 0.024 \\
\hline Normal cognition (27-30) & 132 & 63.5 & 93 & 50.0 & \\
\hline Mild cognitive impairment (21-26) & 61 & 29.3 & 72 & 38.7 & \\
\hline Cognitive impairment (0-20) & 15 & 7.2 & 21 & 11.3 & \\
\hline Composite outcome $(0-26)^{a}$ & 76 & 36.5 & 93 & 50.0 & 0.007 \\
\hline
\end{tabular}

Abbreviation: CMMSE, Cantonese version of Mini-Mental State Examination; SD, standard deviation.

${ }^{\text {a }}$ Composite outcome refers to the prevalence of $\mathrm{MCl}$ plus cognitive impairment

Table 3 Distribution of circadian rhythm parameters in pneumoconiosis patients and community referents

\begin{tabular}{|c|c|c|c|c|c|}
\hline \multirow{3}{*}{$\begin{array}{l}\text { Variable } \\
\text { Percent rhythm }\end{array}$} & \multirow{2}{*}{\multicolumn{2}{|c|}{$\begin{array}{l}\text { Community } \\
\text { referents }(\mathrm{N}=208)\end{array}$}} & \multirow{2}{*}{\multicolumn{2}{|c|}{$\begin{array}{l}\text { Pneumoconiosis } \\
\text { workers }(\mathrm{N}=186)\end{array}$}} & \multirow{3}{*}{$\begin{array}{l}P \text {-value } \\
0.98\end{array}$} \\
\hline & & & & & \\
\hline & 18.1 & $12.8-23.4$ & 17.7 & $13.6-23.6$ & \\
\hline Amplitude & 128.9 & 86.3-181.5 & 113.2 & 79.1-169.9 & 0.13 \\
\hline MESOR & 268.2 & 213.3-327.5 & 236.4 & 194.9-309.5 & 0.008 \\
\hline Acrophase & 14.1 & $12.5-15.6$ & 13.5 & $12.2-14.8$ & 0.029 \\
\hline
\end{tabular}

Values were given as median (interquartile range). Abbreviation: MESOR, midline estimating statistic of rhythm.

Table 4 Associations between circadian activity rhythm and cognitive function in pneumoconiosis patients 


\begin{tabular}{|c|c|c|c|}
\hline Circadian parameters & CMMSE total score & Mild cognitive impairment & Composite outcome ${ }^{a}$ \\
\hline Cases, N & 186 & 72 & 93 \\
\hline \multicolumn{4}{|c|}{ Model 1} \\
\hline \multicolumn{4}{|l|}{ Percent rhythm } \\
\hline$<17.7$ & $0.11(-0.82,1.04)$ & $1.71(0.90,3.24)^{*}$ & $1.31(0.72,2.4)$ \\
\hline \multicolumn{4}{|l|}{ Amplitude } \\
\hline$<113.2$ & $0.00(-0.97,0.96)$ & $1.86(0.96,3.59)$ * & $1.50(0.81,2.78)$ \\
\hline \multicolumn{4}{|l|}{ MESOR } \\
\hline$<236.4$ & $-0.99(-1.96,-0.03)$ ** & $1.71(0.89,3.27)$ & $1.88(1.01,3.51)$ ** \\
\hline \multicolumn{4}{|l|}{ Acrophase } \\
\hline$<13.5$ & $-0.61(-1.55,0.34)$ & $0.80(0.42,1.52)$ & $1.00(0.54,1.83)$ \\
\hline \multicolumn{4}{|c|}{ Model 2} \\
\hline \multicolumn{4}{|l|}{ Percent rhythm } \\
\hline$<17.7$ & $0.49(-0.47,1.44)$ & $1.31(0.64,2.71)$ & $1.03(0.52,2.02)$ \\
\hline \multicolumn{4}{|l|}{ Amplitude } \\
\hline$<113.2$ & $0.29(-0.71,1.29)$ & $1.49(0.70,3.18)$ & $1.29(0.63,2.61)$ \\
\hline \multicolumn{4}{|l|}{ MESOR } \\
\hline$<236.4$ & $-0.85(-1.86,0.15)^{*}$ & $1.66(0.78,3.53)$ & $1.93(0.94,3.97)$ * \\
\hline \multicolumn{4}{|l|}{ Acrophase } \\
\hline$<13.5$ & $-0.28(-1.25,0.69)$ & $0.78(0.37,1.64)$ & $0.90(0.45,1.81)$ \\
\hline
\end{tabular}

Abbreviations: $\mathrm{MCl}$, mild cognitive impairment; CMMSE, Cantonese version of the Mini-Mental State Examination; MESOR, midline estimating statistic of rhythm.

Model 1, adjusted for age (years) and education (years).

Model 2, model 1 further marital status, employment, BMI, stroke, hypertension, diabetes, cardiovascular disease, sleep medication use, family history of dementia, smoking, alcohol drinking, tea drinker, coffee drinker, anxiety, depression, physical activity, waist circumference, percent body fat, handgrip strength and poor sleep (PSQI>5).

${ }^{* *} P<0.05,{ }^{*} P<0.1$.

${ }^{a}$ Composite outcome refers to the prevalence of $\mathrm{MCl}$ plus cognitive impairment

Table 5 Association between circadian rhythm and $\mathrm{MCl}$ or cognitive impairment assessed by CMMSE in study population 


\begin{tabular}{|c|c|c|c|c|c|c|c|c|c|c|}
\hline & \multicolumn{5}{|c|}{ Community referents } & \multicolumn{5}{|c|}{ Pneumoconiosis patients } \\
\hline & $\begin{array}{l}\text { Normal } \\
\text { cognition }\end{array}$ & $\mathrm{MCl}$ & $\begin{array}{l}\text { Composite } \\
\text { outcome }\end{array}$ & $\mathrm{MCl}$ & $\begin{array}{l}\text { Composite } \\
\text { outcome }\end{array}$ & $\begin{array}{l}\text { Normal } \\
\text { cognition }\end{array}$ & $\mathrm{MCl}$ & $\begin{array}{l}\text { Composite } \\
\text { outcome }\end{array}$ & $\mathrm{MCl}$ & $\begin{array}{l}\text { Composite } \\
\text { outcome }\end{array}$ \\
\hline & n (\%) & n (\%) & n (\%) & $\begin{array}{l}\text { OR } \\
(95 \% \\
\mathrm{Cl})^{b}\end{array}$ & $\begin{array}{l}\text { OR (95\% } \\
\text { Cl) })^{b}\end{array}$ & n (\%) & n (\%) & n (\%) & $\begin{array}{l}\text { OR } \\
(95 \% \\
\mathrm{Cl})^{\mathrm{b}}\end{array}$ & $\begin{array}{l}\text { OR }(95 \% \\
\mathrm{Cl})^{\mathrm{b}}\end{array}$ \\
\hline $\mathbf{N}$ & 132 & 61 & 76 & & & 93 & 72 & 93 & & \\
\hline \multicolumn{11}{|l|}{$\begin{array}{l}\text { Percent } \\
\text { rhythm }^{\text {a }}\end{array}$} \\
\hline$\geq 17.8$ & $61(46.2)$ & $\begin{array}{l}38 \\
(62.3)\end{array}$ & 45 (59.2) & $\begin{array}{l}1.00 \\
\text { (ref) }\end{array}$ & 1.00 (ref) & 48 (51.6) & $\begin{array}{l}28 \\
(38.9)\end{array}$ & $43(46.2)$ & $\begin{array}{l}0.74 \\
(0.35 \\
1.55)\end{array}$ & $\begin{array}{l}0.91(0.46, \\
1.81)\end{array}$ \\
\hline$<17.8$ & $71(53.8)$ & $\begin{array}{l}23 \\
(37.7)\end{array}$ & $31(40.8)$ & $\begin{array}{l}0.44 \\
(0.22 \\
0.88) \\
* *\end{array}$ & $\begin{array}{l}0.49(0.26 \\
0.95)^{* *}\end{array}$ & $45(48.4)$ & $\begin{array}{l}44 \\
(61.1)\end{array}$ & $50(53.8)$ & $\begin{array}{l}1.09 \\
(0.53 \\
2.23)\end{array}$ & $\begin{array}{l}1.00(0.50, \\
2.01)\end{array}$ \\
\hline \multicolumn{11}{|c|}{$\begin{array}{l}\text { Amplitude } \\
\text { a }\end{array}$} \\
\hline$\geq 120.8$ & 77 (58.3) & $\begin{array}{l}29 \\
(47.5)\end{array}$ & $33(43.4)$ & $\begin{array}{l}1.00 \\
\text { (ref) }\end{array}$ & 1.00 (ref) & $50(53.8)$ & $\begin{array}{l}28 \\
(38.9)\end{array}$ & 37 (39.8) & $\begin{array}{l}1.14 \\
(0.54 \\
2.38)\end{array}$ & $\begin{array}{l}1.28(0.64, \\
2.55)\end{array}$ \\
\hline$<120.8$ & 55 (41.7) & $\begin{array}{l}32 \\
(52.5)\end{array}$ & $43(56.6)$ & $\begin{array}{l}1.03 \\
(0.52, \\
2.07)\end{array}$ & $\begin{array}{l}1.20(0.62, \\
2.32)\end{array}$ & $43(46.2)$ & $\begin{array}{l}44 \\
(61.1)\end{array}$ & $56(60.2)$ & $\begin{array}{l}1.53 \\
(0.74 \\
3.15)\end{array}$ & $\begin{array}{l}1.62(0.81, \\
3.25)\end{array}$ \\
\hline \multicolumn{11}{|l|}{ MESOR $^{a}$} \\
\hline$\geq 254.8$ & 81 (61.4) & $\begin{array}{l}32 \\
(52.5)\end{array}$ & 37 (48.7) & $\begin{array}{l}1.00 \\
\text { (ref) }\end{array}$ & 1.00 (ref) & $50(53.8)$ & $\begin{array}{l}26 \\
(36.1)\end{array}$ & 30 (32.3) & $\begin{array}{l}1.10 \\
(0.53 \\
2.31)\end{array}$ & $\begin{array}{l}1.10(0.54, \\
2.23)\end{array}$ \\
\hline$<254.8$ & $51(38.6)$ & $\begin{array}{l}29 \\
(47.5)\end{array}$ & 39 (51.3) & $\begin{array}{l}1.18 \\
(0.58 \\
2.4)\end{array}$ & $\begin{array}{l}1.47(0.75 \\
2.87)\end{array}$ & $43(46.2)$ & $\begin{array}{l}46 \\
(63.9)\end{array}$ & 63 (67.7) & $\begin{array}{l}1.71 \\
(0.84 \\
3.46)\end{array}$ & $\begin{array}{l}2.01(1.03, \\
3.94)^{* \star}\end{array}$ \\
\hline \multicolumn{11}{|c|}{$\begin{array}{l}\text { Acrophase } \\
\text { a }\end{array}$} \\
\hline$\geq 13.8$ & 78 (59.1) & $\begin{array}{l}29 \\
(47.5)\end{array}$ & $35(46.1)$ & $\begin{array}{l}1.00 \\
\text { (ref) }\end{array}$ & 1.00 (ref) & $42(45.2)$ & $\begin{array}{l}38 \\
(52.8)\end{array}$ & $42(45.2)$ & $\begin{array}{l}1.90 \\
(0.91 \\
3.98) \\
*\end{array}$ & $\begin{array}{l}1.67(0.82, \\
3.40)\end{array}$ \\
\hline$<13.8$ & $54(40.9)$ & $\begin{array}{l}32 \\
(52.5)\end{array}$ & $41(53.9)$ & $\begin{array}{l}1.08 \\
(0.52 \\
2.25)\end{array}$ & $\begin{array}{l}1.04(0.52 \\
2.09)\end{array}$ & $51(54.8)$ & $\begin{array}{l}34 \\
(47.2)\end{array}$ & $51(54.8)$ & $\begin{array}{l}0.96 \\
(0.44 \\
2.08)\end{array}$ & $\begin{array}{l}1.13(0.55, \\
2.31)\end{array}$ \\
\hline
\end{tabular}

a Using median as the cutoff point.

Abbreviations: $\mathrm{MCl}$, mild cognitive impairment; CMMSE, Cantonese version of the Mini-Mental State Examination; MESOR, midline estimating statistic of rhythm; OR, odds ratio; $\mathrm{Cl}$, confidence interval.

b, adjusted for age (years) and education (years), marital status, employment, BMl, stroke, hypertension, diabetes, cardiovascular disease, sleep medication use, family history of dementia, smoking, alcohol drinking, tea drinker, coffee drinker, anxiety, depression, physical activity, waist circumference, percent body fat, handgrip strength and poor sleep (PSQI>5).

${ }^{*} P<0.05,{ }^{*} P<0.1$. 


\section{Supplementary Files}

This is a list of supplementary files associated with this preprint. Click to download.

- Additionalfiles.docx 